British Journal of Nutrition (2022), 127, 1888-1897

doi:10.1017/S0007114521003597

(C) The Author(s), 2021. Published by Cambridge University Press on behalf of The Nutrition Society. This is an Open Access article, distributed under the terms of the Creative Commons Attribution licence (https://creativecommons.org/licenses/by/4.0/), which permits unrestricted re-use, distribution, and reproduction in any medium, provided the original work is properly cited.

\title{
Associations between bedtime eating or drinking, sleep duration and wake after sleep onset: findings from the American time use survey
}

\author{
Su I Iao ${ }^{1}$, Erica Jansen ${ }^{2}$, Kerby Shedden ${ }^{1}$, Louise M. O’Brien ${ }^{3}$, Ronald D. Chervin ${ }^{3}$, Kristen L. Knutson ${ }^{4}$ and \\ Galit Levi Dunietz ${ }^{2,3 *}$ \\ ${ }^{1}$ Department of Statistics, University of Michigan, Ann Arbor, MI, USA \\ ${ }^{2}$ Department of Nutritional Sciences, School of Public Health, University of Michigan, Ann Arbor, MI, USA \\ ${ }^{3}$ Division of Sleep Medicine, Department of Neurology, University of Michigan, Ann Arbor, MI, USA \\ ${ }^{4}$ Department of Neurology, Northwestern University Feinberg School of Medicine, Chicago, IL, USA
}

(Submitted 20 April 2021 - Final revision received 30 August 2021 - Accepted 6 September 2021 - First published online 13 September 2021)

Abstract

Sleep hygiene recommendations discourage eating before bedtime; however, the impact of mealtime on sleep has been inconsistent. We examined gender-stratified associations between eating or drinking $<1,<2$ and $<3 \mathrm{~h}$ before bedtime, sleep duration and wake after sleep onset (WASO >30 min). This study utilised 2003-2018 data from the American Time Use Survey, a nationally representative sample of USA residents aged $\geq 15$ years. Participants recorded weekday/weekend activities during a 24-h period. Age-specific sleep duration and WASO were estimated categorically and continuously. Eating or drinking were identified from all activities recorded $<1,<2$ and $<3 \mathrm{~h}$ before bedtime. Mean \pm sE sleep duration was $8.0 \pm 0.006 \mathrm{~h}$, and $6 \%$ of participants ate or drank $<1 \mathrm{~h}$ prior to weekdays bedtime. Overall, eating or drinking $<1 \mathrm{~h}$ prior to bedtime was associated with longer weekdays sleep duration. Women and men who ate or drank $<1 \mathrm{~h}$ before bedtime, $v$. those who did not, had $35 \mathrm{~min}(95 \% \mathrm{CI}(30,39))$ and $25 \mathrm{~min}(95 \% \mathrm{CI}(21,29))$ longer sleep duration, respectively, as well as increased odds of WASO; women $(\mathrm{OR}=2 \cdot 03,95 \% \mathrm{CI}(1 \cdot 66,2 \cdot 49))$ and men $(\mathrm{OR}=2 \cdot 64,95 \% \mathrm{CI}(2 \cdot 08,3 \cdot 36))$. As the interval of eating or drinking prior to bedtime expanded, odds of short and long sleep durations and WASO decreased. This population-based data linked eating or drinking $<1 \mathrm{~h}$ before bedtime to longer sleep duration, but increased WASO. Eating or drinking further from bedtime lowers the odds of short and long sleep duration and WASO. Causal pathways are difficult to discern, though inefficient sleep after late-night eating could increase WASO and trigger compensatory increases in sleep duration.

Key words: Mealtime: Sleep: Sleep duration: Wake after sleep onset: Sleep fragmentation

The American Academy of Sleep Medicine recommends at least $7 \mathrm{~h}$ of nocturnal sleep for adults aged 18-60 years to sustain health ${ }^{(1)}$. The contribution of short sleep to poor physical and mental health has been reported consistently ${ }^{(2-5)}$. Further evidence has also associated longer sleep duration, defined as $\geq 9 \mathrm{~h}$, with cardiometabolic morbidities, including diabetes, CVD and mortality ${ }^{(6)}$. Despite these known associations, sleep duration has been declining among USA adults ${ }^{(7)}$, and current prevalence of short sleep duration is estimated at about $35 \%^{(8)}$. Whereas prevalence of short sleep duration among USA adults may be slightly decreasing, prevalence of long sleep duration may be increasing ${ }^{(9)}$.

Wake after sleep onset (WASO) is a key symptom of chronic insomnia $^{(10)}$ and significantly correlates with poor sleep quality $^{(11)}$. Reported by $5-10 \%$ of adults, difficulty to maintain sleep is an insomnia symptom characterised by polysomnography as WASO $\geq 30 \mathrm{~min}$, which is more common among older adults and women ${ }^{(12)}$. Poor mental health and physical morbidity have been associated with WASO in paediatric, pregnant, adult and older adult populations ${ }^{(13-16)}$.

Sleep duration and continuity are influenced by sleep hygiene ${ }^{(17)}$. To promote healthy sleep, sleep hygiene recommendations commonly suggest avoiding electronic screens before bedtime; sleeping in a quiet, dark, cool environment and refraining from using the bedroom for activities other than sleeping or intimacy ${ }^{(18,19)}$. Good sleep hygiene practices also discourage eating or drinking before bed, in particular large or spicy meals, alcohol and caffeinated or carbonated beverages ${ }^{(20)}$. In contrast, light eating before bed is permissible ${ }^{(18)}$. Yet, other than for alcohol and caffeine ${ }^{(21,22)}$, evidence to support dietary recommendations is scarce. Associations of nighttime snacking and irregular or late meal times with poor sleep quality ${ }^{(23)}$, short

Abbreviations: ATUS, American Time Use Survey; WASO, wake after sleep onset.

*Corresponding author: Galit Levi Dunietz, email gldt@med.umich.edu 
sleep duration ${ }^{(24-26)}$ and long sleep duration have been suggested $^{(27)}$. However, most of these reports lack a time referent for when nighttime eating occurs in relation to bedtime. A recent study examined the impact of mealtime within $3 \mathrm{~h}$ of bedtime on sleep quality and duration in 793 young adults. This study reported positive associations between mealtime and nocturnal awakenings, but not short sleep duration ${ }^{(23)}$. Population-level and gender-specific associations between mealtime and subsequent sleep are rare. Therefore, this study examined overall and gender-specific relationships between weekdays eating or drinking $<1,<2$ and $<3 \mathrm{~h}$ before bed, sleep duration and WASO.

\section{Methods}

\section{Study population: the American time use survey}

The American Time Use Survey (ATUS) conducted by the USA. Census Bureau is an annual and cross-sectional survey in the USA sponsored by the Bureau of Labor Statistics since $2003^{(28)}$. Except the 2003 sample of $n 20720$, data from the ATUS have an average sample size of $n 12572$ (range $n 9593$ to $n 13$ 973) in subsequent years. ATUS participants represent the population of USA residents, aged 15 to 85 years. To describe activities along each of the seven weekdays, ATUS was distributed evenly between weekdays and weekends. In an annual phone interview, ATUS participants were asked to report their activities during a $24-\mathrm{h}$ period ( 04.00 to 04.00 on the interview day) and were randomly selected to report weekdays or weekend activities. However, participants who woke up after 04.00 continued to report activities up to their wake time. Each participant reported either the duration or the start and end time of each activity. The primary analysis focused on the data from 2003 to 2018 and was restricted to weekday respondents (Sunday-Thursday) with nocturnal sleep schedules ( $\left.n \begin{array}{lll}n & 124 & 239\end{array}\right)$ to examine sleep patterns. Subsequent analysis compared weekend and weekdays sleep patterns.

\section{Exposure: eating or drinking $<1 \mathrm{~h}$ before bedtime}

Eating or drinking activities (activity code: 110 101) were identified from all activities recorded within 1, 2 and $3 \mathrm{~h}$ prior to bedtime. ATUS respondents were classified into two groups based on the presence or absence of eating or drinking activities $<1,<2$ and $<3 \mathrm{~h}$ prior to their primary sleep period. Participants did not record the type of food or drink consumed, only that they had engaged in eating or drinking.

\section{Primary sleep period}

For each ATUS participant, the primary sleep was defined as the period of sleep beginning after 18.00 such that the $5 \mathrm{~h}$ following sleep onset contain at least three total hours of sleep. This algorithm identified nocturnal sleep and excluded ATUS participants without primary sleep period or those who reported daytime sleep, a common pattern among women and men who work in shifts.

\section{Outcome measures}

Sleep duration on weekdays. Survey respondents recorded their sleep with an activity code 010101 . Within the primary sleep period, sleep duration was calculated by adding all recorded sleep periods. In this analysis, sleep duration was first considered as a continuous outcome and later as a three-category outcome, i.e., short sleep, sufficient sleep and long sleep, according to the age-specific American Academy of Sleep Medicine recommendations ${ }^{(29)}$. For participants 15-17 years, short sleep, sufficient sleep and long sleep corresponded to $<8 \mathrm{~h}, 8-10 \mathrm{~h}$ and $>10 \mathrm{~h}$, respectively. For those $\geq 18$ years, short sleep, sufficient sleep and long sleep were defined as $<7 \mathrm{~h}, 7-9 \mathrm{~h}$ and $>9 \mathrm{~h}$, respectively. Finally, for older adults $\geq 65$ years, short sleep, sufficient sleep and long sleep corresponded to $<7 \mathrm{~h}, 7-8 \mathrm{~h}$ and $>8 \mathrm{~h}$, respectively. Total sleep duration ranged between 3 and $14 \mathrm{~h}$. Sleep duration beyond $14 \mathrm{~h}$ was reported by $0.2 \%$ of respondents.

Self-report Wake After Sleep Onset on weekdays. Wake after sleep onset is a measure of wakefulness periods that occur after the onset of sleep. WASO was defined for this analysis as any non-sleep activities of $\geq 30 \mathrm{~min}$ within the primary sleep period, such that sleep was reported before and after the indicated WASO. This threshold is consistent with the length of sleep-onset insomnia thought to be clinically significant if it recurs on a regular basis ${ }^{(30)}$. We have also computed minutes of WASO as a continuous outcome.

The five most frequent activities that appeared as non-sleep during the primary sleep period were watching television and movies; physical care for household children; washing, dressing and grooming oneself; sleeplessness and eating or drinking (activity codes, respectively: 120 303, 030 101, 010 201, 010 102, 110 101). The total duration of WASO during the primary sleep period was also calculated for those respondents with $\geq 30 \mathrm{~min}$ of WASO.

\section{Potential confounders}

Selection of covariates was guided by causal diagrams based on their relevance to eating or drinking behaviours, sleep duration and WASO. The following demographic characteristics were included as potential confounders - gender (men, women), age (15-22, 23-30, 31-50, 51-64, 65+ years), race (White non-Hispanic, Black non-Hispanic, Hispanic and Other), education (less than high school, high school graduate, college graduate, Master's degree or higher), work status (employed, unemployed and not in labour force), cohabitation (spouse present, unmarried partner present and no partner) and the presence of children $<18$ years in the household (yes/no). Age categories were selected to reflect youth, young adulthood, early middle age and older adults, in an effort to compare life stages that may be associated with different amounts and patterns of sleep. The reported day of the week and survey year were also added as covariates to the regression models.

\section{Statistical analysis}

Estimation methods appropriate for complex surveys were used to estimate the frequencies and proportion of ATUS respondents 
and those who reported eating or drinking $<1 \mathrm{~h}$ prior to their bedtime, by socio-demographic characteristics, i.e. gender, age, race, education, work status, cohabitation and the presence of children $<18$ years in the household. Appropriate ATUS survey weights were applied in all analyses to yield nationally representative estimates.

Mean weekdays sleep duration and proportion of ATUS respondents who reported WASO were also estimated in relation to these demographic predictors. Bivariate analyses described the proportion of ATUS respondents who reported eating or drinking $1 \mathrm{~h}$ prior to bedtime by gender and age and the duration of WASO by gender and age.

Linear and multinomial logistic regression models were used to examine the associations of eating or drinking $<1 \mathrm{~h}$ prior to bedtime and sleep duration or WASO, as continuous or categorical outcomes, respectively. Adjusted models controlled for gender, age, race, education, work status, cohabitation, the presence of children $<18$ years in the household, day of the week reported and survey year. To evaluate whether gender differences modified the association between eating or drinking prior to bedtime, sleep duration and WASO, we fitted genderstratified regression models and conducted formal interaction analysis, by adding to our regression models a product term of eating or drinking and gender variables and evaluated its statistical significance as a predictor of sleep measures.

To examine the robustness of our findings, we conducted sensitivity analyses by exclusion of activities within the primary sleep period, unlikely to be related to bedtime eating or drinking. Specifically, within the primary sleep period, we excluded physical care for household children or medical care for household children from WASO. As a second step, we examined the association between bedtime eating or drinking and WASO redefined as a continuous variable. Next, we evaluated the associations between bedtime eating or drinking and sleep duration in respondents who did not report WASO. Exclusion of these respondents allowed examinations of bedtime eating or drinking in relation to continuous sleep duration, i.e. not been affected by WASO. In subsequent analysis of weekdays and weekend differences, we examined the influence of eating or drinking prior to bedtime in relation to sleep duration and WASO on weekends. Finally, we examined eating or drinking activities $<2$ and $<3 \mathrm{~h}$ prior to bedtime in relation to sleep duration and WASO.

All data analyses procedures were conducted using survey package in $\mathrm{R}$ (version 3.5.3) and surveylogistic in SAS (version 9.4).

\section{Results}

More than 201000 USA residents participated in ATUS surveys between 2003 and 2018. After exclusion of those without primary sleep period, primary sleep period before 18.00 and weekend respondents, the final sample size included 124239 participants (Fig. 1). Among the 124239 ATUS survey respondents, $53 \%$ were women, $59 \%$ were aged 50 or younger and the majority (69\%) were white, non-Hispanic. Eating or drinking $1 \mathrm{~h}$ prior to bedtime was reported by $6.4 \%$ of survey

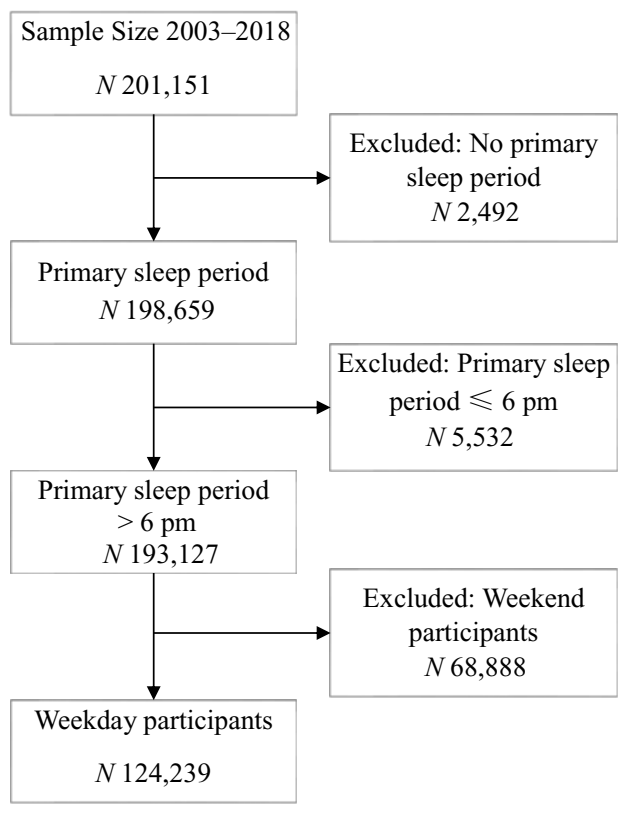

Fig. 1. American Time Use Survey (ATUS) participants and final sample size 2003-2018.

participants, $5.5 \%$ of women and $7.5 \%$ of men. With increasing age, the proportion of eating or drinking $1 \mathrm{~h}$ prior to bedtime declined. The proportion of Americans who ate $1 \mathrm{~h}$ prior to bedtime was higher among employed respondents $(7 \cdot 3 \%)$ than among those who were unemployed (6.7\%) or not in labour force $(4.8 \%)$ (Table 1$)$.

Mean weekdays sleep duration was somewhat similar for women and men and among racial/ethnic groups. A U-shape trend in mean sleep duration was observed in relation to age, such that those aged 31-64 years had lowest sleep duration (7.8 h). Employed Americans reported shorter weekdays sleep than did the unemployed and those not in the labour force (46 min and 33 min longer, respectively). A higher proportion of women reported WASO than men (2.3\% v. 1.4\%), and lowest WASO was reported among respondents in the 15-22 age group (1.1\%) (Table 1$)$

The proportion of eating or drinking activities reported $<1 \mathrm{~h}$ prior to weekdays bedtime declined along increasing age categories, for both men and women respondents; however, men were more likely to report eating or drinking activities than women along the lifespan (Fig. 2). Among all respondents with reported WASO $\geq 30 \mathrm{~min}$ on weekdays, all age groups had on average at least an hour of WASO, except women aged 23-50 years (Fig. 3). The most frequent activities reported during WASO were watching TV and movies, physical care for children, washing, dressing and grooming, sleeplessness and eating or drinking. Description of duration and timing of activities reported by ATUS respondents during weekdays WASO periods, as well as their demographic correlates identified as potential confounders are presented in Table 2.

Linear regression analysis suggested eating or drinking $<1 \mathrm{~h}$ prior to bedtime on weekdays was associated with $30 \mathrm{~min}$ longer sleep on average (95\% CI 27, 33). The association remained statistically significant after adjusting for gender, age, 
Table 1. Socio-demographic correlates of eating or drinking prior to bedtime, sleep duration and wake after sleep onset (WASO) among 124239 participants of the American time use survey

(Numbers and percentages; mean values and standard deviations)

\begin{tabular}{|c|c|c|c|c|c|c|}
\hline $\begin{array}{l}\text { Socio-demographic } \\
\text { predictors }\end{array}$ & $n$ & $\%$ & Ate $<1 \mathrm{~h}$ before bed, $(\%)^{\star}, \dagger$ & Mean sleep duration (h) & SE & Wake after sleep onset $(\%)^{*}, \dagger$ \\
\hline \multicolumn{7}{|l|}{ Gender } \\
\hline Women & 70125 & 53 & $5 \cdot 5$ & $8 \cdot 1$ & 0.008 & $2 \cdot 3$ \\
\hline Men & 54114 & 47 & 7.5 & 7.9 & 0.009 & 1.4 \\
\hline \multicolumn{7}{|l|}{ Age group, years $(y)$} \\
\hline $15-22$ & 10358 & 12 & $9 \cdot 0$ & $8 \cdot 7$ & 0.022 & $1 \cdot 1$ \\
\hline $23-30$ & 12908 & 12 & 7.9 & $8 \cdot 2$ & 0.018 & $2 \cdot 2$ \\
\hline $51-64$ & 27730 & 23 & $5 \cdot 7$ & $7 \cdot 8$ & 0.012 & 1.8 \\
\hline $65+$ & 24900 & 18 & $3 \cdot 9$ & $8 \cdot 2$ & 0.013 & $2 \cdot 1$ \\
\hline \multicolumn{7}{|l|}{ Race/ethnicity } \\
\hline White, non-Hispanic & 85187 & 69 & $5 \cdot 4$ & $7 \cdot 9$ & 0.007 & 1.9 \\
\hline Black, non-Hispanic & 16070 & 12 & $7 \cdot 4$ & $7 \cdot 9$ & 0.019 & $2 \cdot 5$ \\
\hline Hispanic & 16704 & 14 & $9 \cdot 6$ & $8 \cdot 3$ & 0.017 & $1 \cdot 3$ \\
\hline Otherł & 6278 & 5 & 8.6 & $8 \cdot 0$ & 0.026 & 1.5 \\
\hline \multicolumn{7}{|l|}{ Educational status } \\
\hline College graduate & 38350 & 29 & $5 \cdot 6$ & $7 \cdot 8$ & 0.009 & $2 \cdot 0$ \\
\hline $\begin{array}{l}\text { Master's degree or } \\
\text { higher }\end{array}$ & 12688 & 9 & $5 \cdot 8$ & $7 \cdot 7$ & 0.015 & 1.9 \\
\hline \multicolumn{7}{|l|}{ Work status } \\
\hline Employed & 76627 & 62 & $7 \cdot 3$ & $7 \cdot 8$ & 0.007 & $1 \cdot 6$ \\
\hline Unemployed & 5719 & 5 & $6 \cdot 7$ & 8.5 & 0.030 & 1.5 \\
\hline Not in labour force & 41893 & 33 & 4.8 & 8.3 & 0.011 & $2 \cdot 3$ \\
\hline \multicolumn{7}{|l|}{ Cohabitation } \\
\hline Spouse present & 62863 & 55 & 5.9 & $7 \cdot 9$ & 0.007 & $2 \cdot 1$ \\
\hline $\begin{array}{l}\text { Unmarried partner } \\
\text { present }\end{array}$ & 4041 & 4 & $8 \cdot 4$ & $8 \cdot 1$ & 0.032 & 1.4 \\
\hline \multicolumn{7}{|l|}{$\begin{array}{l}\text { No spouse or } \\
\text { unmarried }\end{array}$} \\
\hline Partner present & 57335 & 41 & $6 \cdot 9$ & $8 \cdot 2$ & 0.010 & 1.6 \\
\hline \multicolumn{7}{|l|}{$\begin{array}{l}\text { Presence of } \\
\text { children }<18 \text { years }\end{array}$} \\
\hline Yes & 54274 & 40 & $7 \cdot 1$ & $8 \cdot 0$ & 0.009 & $2 \cdot 1$ \\
\hline
\end{tabular}

* Weighted means and proportions for percentage of respondents who reported WASO $\geq 30 \mathrm{~min}$

$\dagger$ All bivariate associations are statistically significant, $P<0.05$.

$\ddagger$ Other: Asian only, Hawaiian/Pacific Islander only or bi-racial.

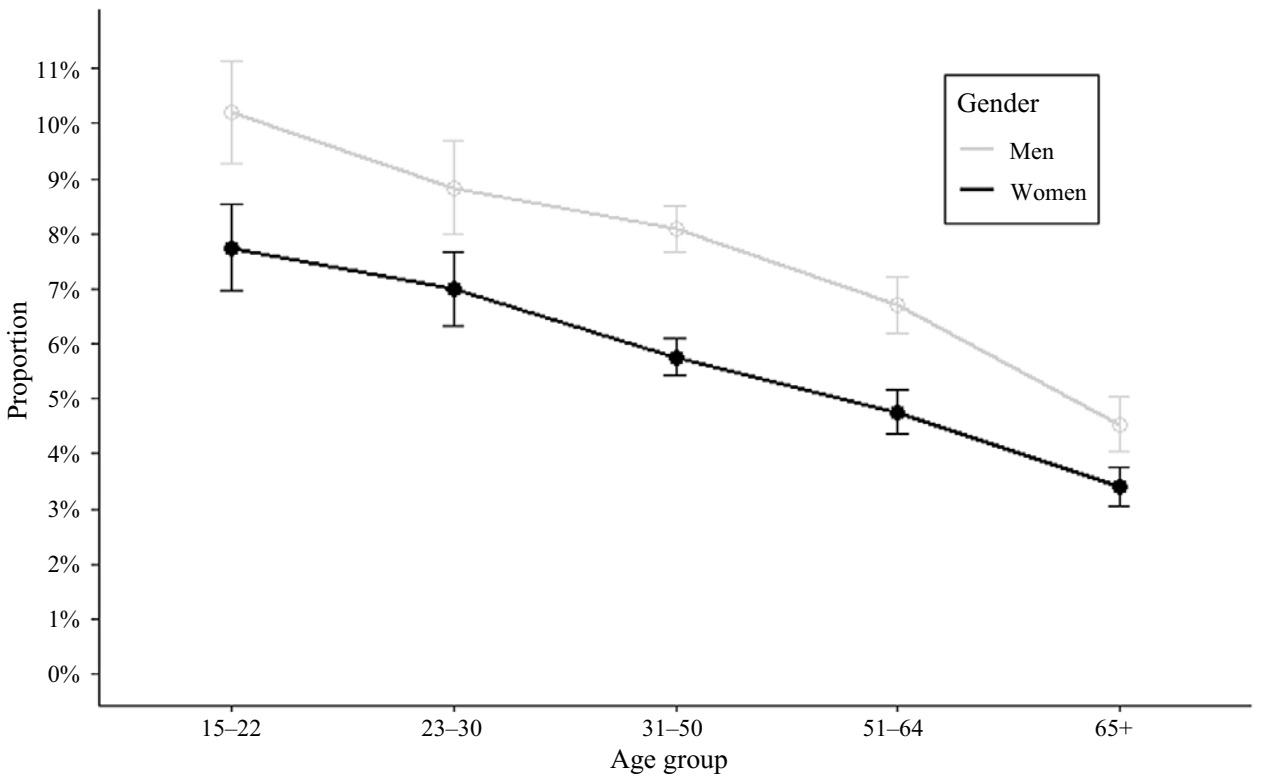

Fig. 2. Proportions of Americans eating or drinking $<1 \mathrm{~h}$ before bedtime by gender and age. 

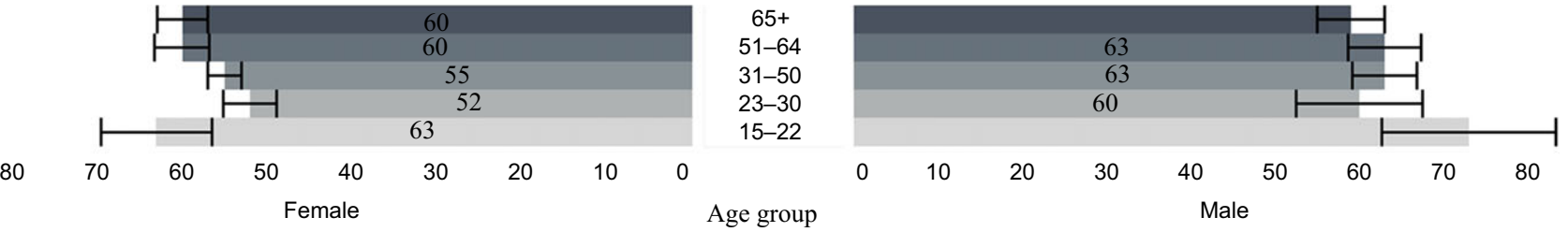

Fig. 3. Mean weekdays wake after sleep onset (WASO) minutes by gender and age among those with WASO $\geq 30$ min.

Table 2. Five frequent weekday activities during wake after sleep onset (WASO) as reported by 2481 American Time Use Survey (ATUS) participants who reported WASO > 30 min on weekdays: duration, timing and demographic correlates (Numbers and percentages; mean values with their standard errors)

\begin{tabular}{|c|c|c|c|c|c|c|}
\hline & $n$ & $\%$ & Mean duration (min) & SE & Timing & Demographic \\
\hline Watching television and movies & 665 & 26 & 59.0 & 1.38 & 23:04 & $\begin{array}{l}\text { Gender: women, } 55 \% \\
\text { Age: } 65+, 30 \% \\
\text { Race: white only, } 64 \% \\
\text { Education: HS graduates, } 50 \% \\
\text { Employed: } 55 \% \\
\text { Spouse present: } 54 \% \\
\text { No child < } 18 \text { at home: } 70 \%\end{array}$ \\
\hline Physical care for household children & 519 & 20 & $41 \cdot 3$ & 1.09 & 00:53 (next day) & $\begin{array}{l}\text { Gender: women, } 86 \% \\
\text { Age: } 31-50,51 \% \\
\text { Race: white only, } 71 \% \\
\text { Education: College graduates, } 55 \% \\
\text { Employed: } 61 \% \\
\text { Spouse present: } 82 \% \\
\text { Child }<18 \text { at home: } 100 \%\end{array}$ \\
\hline Washing, dressing and grooming oneself & 455 & 19 & $20 \cdot 3$ & 0.82 & $23: 30$ & $\begin{array}{l}\text { Gender: women, } 61 \% \\
\text { Age: } 65+, 32 \% \\
\text { Race: white only, } 65 \% \\
\text { Education: } \mathrm{HS} \text { graduates, } 47 \% \\
\text { Employed: } 51 \% \\
\text { Spouse present: } 55 \% \\
\text { No child < } 18 \text { at home: } 67 \%\end{array}$ \\
\hline Sleeplessness & 308 & 13 & 49.7 & $1 \cdot 76$ & 01:04 (next day) & $\begin{array}{l}\text { Gender: women, } 67 \% \\
\text { Age: } 31-50,32 \% \\
\text { Race: white only, } 75 \% \\
\text { Education: HS graduates, } 50 \% \\
\text { Employed: } 50 \% \\
\text { Spouse present: } 59 \% \\
\text { No child < } 18 \text { at home: } 62 \%\end{array}$ \\
\hline Eating or drinking & 173 & 8 & $22 \cdot 6$ & 1.5 & $23: 30$ & $\begin{array}{l}\text { Gender: women, } 52 \% \\
\text { Age: } 51-64,29 \% \\
\text { Race: white only, } 62 \% \\
\text { Education: HS graduates, } 50 \% \\
\text { Employed: } 51 \% \\
\text { Spouse present: } 50 \% \\
\text { No child < } 18 \text { at home: } 69 \%\end{array}$ \\
\hline
\end{tabular}

HS, High School.

race, education status, work status, cohabitation and the presence of children $<18$ years in the household, day of the week and survey year. An interaction analysis showed significant gender differences in the association between eating or drinking $<1 \mathrm{~h}$ prior to bedtime and mean weekdays sleep duration $(P<0.001)$. Unadjusted gender-stratified analyses showed a stronger association between eating $<1 \mathrm{~h}$ before bed and weekdays sleep duration among women than men (37v. 26 min longer compared with those who did not eat before bed). In adjusted multinomial logistic regression analysis, eating or drinking $<1 \mathrm{~h}$ prior to bedtime was associated with lower odds of short sleep duration on weekdays (odds ratio $(\mathrm{OR})=0.88,95 \% \mathrm{CI}: 0.81,0.94)$ and increased odds of long sleep $(\mathrm{OR}=1.79,95 \% \mathrm{CI}: 1.67,1.91)$. These results were similar for women and men. Americans who ate $<1 \mathrm{~h}$ prior to bedtime were more than twice as likely to report weekdays WASO in comparison with those who did not have eating or drinking activities (OR $=2 \cdot 26,95 \% \mathrm{CI}: 1.93,2 \cdot 64)$. These associations did not vary in a statistically significant manner by gender; $\mathrm{OR}=2.03(95 \%$ CI $1.66,2.49)$ for women $v$. OR $=2.64(95 \%$ $2 \cdot 08,3 \cdot 36$ ) for men. Eating or drinking $<1 \mathrm{~h}$ prior to weekdays bedtime was significantly associated with an increase of $13 \mathrm{~min}$ of WASO in men. A stratified analyses by weekdays and weekends suggest that women and men who ate or drank $<1 \mathrm{~h}$ prior to their bedtime had a longer sleep duration; weekdays - $35 \mathrm{~min}$, $95 \% \mathrm{CI}(30,39)$ and $25 \mathrm{~min} 95 \% \mathrm{CI}(21,29)$, for women and men, respectively; weekends - $31 \mathrm{~min}, 95 \% \mathrm{CI}(25,38)$ and $15 \mathrm{~min}$ $95 \%$ CI $(9,21)$ for women and men, respectively. Odds of 
Table 3. Associations of eating or drinking prior to bedtime with weekdays and weekend sleep duration and wake after sleep onset (WASO) among 124239 participants of the American time use survey

(Odds ratio and $95 \%$ confidence intervals)

\begin{tabular}{|c|c|c|c|c|c|c|c|c|c|c|}
\hline & \multicolumn{2}{|c|}{$\begin{array}{c}\text { Sleep } \\
\text { duration* }\end{array}$} & \multicolumn{2}{|c|}{ Short sleep $\dagger, \ddagger$} & \multicolumn{2}{|c|}{ Long sleep†,‡ } & \multicolumn{2}{|c|}{ WASO* } & \multicolumn{2}{|c|}{ WASO $\geq 30 \mathrm{~min} \S, \|$} \\
\hline & Beta & $95 \% \mathrm{Cl}$ & Odds ratio & $95 \% \mathrm{Cl}$ & Odds ratio & $95 \% \mathrm{Cl}$ & Odds ratio & $95 \% \mathrm{Cl}$ & Odds ratio & $95 \% \mathrm{Cl}$ \\
\hline \multicolumn{11}{|l|}{$\begin{array}{l}\text { All respondents } \\
\text { Ate }<1 \mathrm{~h} \text { before } \\
\text { bedtime }\end{array}$} \\
\hline $\begin{array}{l}\text { Crude model } \\
\text { Adjusted model }\end{array}$ & 30 & $27,33^{*}$ & 0.90 & $0.83,0.96^{*}$ & 1.55 & $1.45,1 \cdot 65^{\star}$ & 8.24 & $4.54,11.95^{\star}$ & 2.00 & $1 \cdot 72,2 \cdot 33^{*}$ \\
\hline $\begin{array}{l}\text { Weekdays } \\
\text { Weekend }\end{array}$ & $\begin{array}{l}29 \\
23\end{array}$ & $\begin{array}{l}26,32^{\star} \\
18,27^{\star}\end{array}$ & $\begin{array}{l}0.88 \\
1.03\end{array}$ & $\begin{array}{l}0.81,0.94^{*} \\
0.92,1.15\end{array}$ & $\begin{array}{l}1.79 \\
1.49\end{array}$ & $\begin{array}{l}1.67,1.91^{*} \\
1.37,1.61^{*}\end{array}$ & $\begin{array}{l}7.73 \\
7.04\end{array}$ & $\begin{array}{l}4 \cdot 07,11 \cdot 39^{*} \\
1 \cdot 72,12 \cdot 35^{\star}\end{array}$ & $\begin{array}{l}2 \cdot 26 \\
1.74\end{array}$ & $\begin{array}{l}1 \cdot 93,2 \cdot 64^{\star} \\
1 \cdot 39,2 \cdot 18^{\star}\end{array}$ \\
\hline $\begin{array}{l}\text { Women } \\
\text { Ate }<1 \mathrm{~h} \text { before } \\
\text { bedtime }\end{array}$ & & & & & & & & & & \\
\hline $\begin{array}{c}\text { Crude model } \\
\text { Adjusted modelף }\end{array}$ & 37 & $32,41^{*}$ & 0.85 & $0.76,0.95^{\star}$ & 1.60 & $1.46,1 \cdot 75^{\star}$ & 4.77 & $0 \cdot 38,9 \cdot 17^{*}$ & 1.94 & $1 \cdot 58,2 \cdot 37^{\star}$ \\
\hline $\begin{array}{l}\text { Weekdays } \\
\text { Weekend }\end{array}$ & $\begin{array}{l}35 \\
31\end{array}$ & $\begin{array}{l}30,39^{*} \\
25,38^{*}\end{array}$ & $\begin{array}{l}0.84 \\
0.98\end{array}$ & $\begin{array}{l}0.75,0.94^{*} \\
0.83,1.16\end{array}$ & $\begin{array}{l}1.80 \\
1.62\end{array}$ & $\begin{array}{l}1.63,1.97^{*} \\
1.43,1.82^{*}\end{array}$ & $\begin{array}{l}4.15 \\
7.77\end{array}$ & $\begin{array}{c}-0.25,8 \cdot 54 \\
1.25,14 \cdot 30^{*}\end{array}$ & $\begin{array}{l}2.03 \\
1.89\end{array}$ & $\begin{array}{l}1.66,2.49^{\star} \\
1.41,2.53^{\star}\end{array}$ \\
\hline $\begin{array}{l}\text { Men } \\
\text { Ate }<1 \mathrm{~h} \text { before } \\
\text { bedtime }\end{array}$ & & & & & & & & & & \\
\hline $\begin{array}{c}\text { Crude model } \\
\text { Adjusted model }\end{array}$ & 26 & $22,30^{*}$ & 0.91 & $0.83,1.01$ & 1.55 & $1.42,1.69^{*}$ & $12 \cdot 79$ & $6 \cdot 48,19 \cdot 10^{*}$ & $2 \cdot 32$ & $1 \cdot 83,2 \cdot 93^{*}$ \\
\hline Weekdays & 25 & $21,29^{*}$ & 0.90 & $0.82,0.99^{*}$ & 1.78 & $1.62,1.95^{*}$ & $13 \cdot 28$ & $7 \cdot 19,19 \cdot 37^{*}$ & 2.64 & $2 \cdot 08,3 \cdot 36^{*}$ \\
\hline Weekend & 15 & $9,21^{*}$ & 1.07 & $0.91,1.25$ & 1.38 & $1.23,1.55^{*}$ & 6.76 & $-2 \cdot 08,15 \cdot 60$ & 1.56 & $1 \cdot 09,2 \cdot 23^{*}$ \\
\hline
\end{tabular}

* From a linear regression model with sleep duration or WASO in minutes as the outcome and eating or drinking $<1 \mathrm{~h}$ before bed as a dichotomous predictor.

† From a multinomial logistic model with short sleep duration, sufficient sleep duration and long sleep duration as categorical outcomes (sufficient sleep was the reference) and eating or drinking $<1 \mathrm{~h}$ before bed as a dichotomous predictor.

‡ For participants 15-17 years, short sleep, sufficient sleep and long sleep corresponded to $<8 \mathrm{~h}, 8-10 \mathrm{~h}$ and $>10 \mathrm{~h}$, respectively. For those $\geq 18$ years, short sleep, sufficient sleep and long sleep were defined as $<7 \mathrm{~h}, 7-9 \mathrm{~h}$ and $>9 \mathrm{~h}$, respectively. Finally, for older adults $>65$ years, short sleep, sufficient sleep and long sleep corresponded to $<7 \mathrm{~h}, 7-8 \mathrm{~h}$ and $>8 \mathrm{~h}$, respectively. (Reference: Hirshkowitz M et al. (2015). National Sleep Foundation's sleep time duration recommendations: methodology and results summary. Sleep Health 1, 40-43.)

$\S$ From a logistic regression model with WASO $\geq 30 \mathrm{~min}$ as the dichotomous outcome and eating or drinking $<1 \mathrm{~h}$ before bed as a dichotomous predictor.

II WASO = wake after sleep onset $\geq 30 \mathrm{~min}$

If Adjusted for gender, age, race, education, work status, cohabitation, the presence of children $<18$ years in the household, day of the week and survey year.

WASO were higher for women and men who ate or drank $<1 \mathrm{~h}$ prior to their bedtime (Table 3 ).

Sensitivity analyses excluding activities that caused the awakening, e.g. childcare, strengthen the associations between eating or drinking $<1 \mathrm{~h}$ prior to bedtime and WASO for all respondents, women separately and men separately; $\mathrm{OR}=2.47(2 \cdot 10,2.91)$, $2.33(1.87,2.91)$ and $2.78(2.18,3.56)$, respectively (results not shown).

After exclusion of all ATUS respondents who reported WASO, associations between eating and drinking $<1 \mathrm{~h}$ prior to bedtime and long sleep remained significant among both women and men. Associations with short sleep duration were apparent in women and approached statistical significance in men (Table 4).

Associations of eating or drinking $<1,<2$ and $<3 \mathrm{~h}$ prior to bedtime with sleep duration and WASO are presented in Table 5 . The likelihood of both short and long sleep durations decreased with widening intervals of eating or drinking prior to bedtime. Women who reported eating or drinking $<2 \mathrm{~h}$ and $<3 \mathrm{~h}$ prior to bedtime had 0.71 and 0.6 odds for short sleep duration in comparison with those who did not eat or drink during that time. Similarly, the odds of short sleep duration among men were 0.75 and 0.66 for eating or drinking $<2 \mathrm{~h}$ and $<3 \mathrm{~h}$ prior to bedtime, respectively. Overall, as the interval of eating or drinking prior to bedtime lengthen, the odds of short and long sleep durations and WASO decreased (Table 5).
To examine whether this trend persists as intervals between eating or drinking and bedtime continue to expand, we conducted additional analyses with $<4,<5,<6$ and $<7 \mathrm{~h}$ intervals. Indeed, the decreasing associations trend continued with widening intervals; however, the protective effect against short sleep duration was most pronounced when eating or drinking was reported $<4 \mathrm{~h}$ prior to bedtime $(\mathrm{OR}=0.59,95 \% \mathrm{CI}$ $(0 \cdot 57,0 \cdot 61)$, Table 5). Similarly, the odds of WASO and long sleep duration approached a plateau when last eating or drinking activities were $<6 \mathrm{~h}$ before bedtime (OR $=1 \cdot 29,95 \% \mathrm{CI}(1 \cdot 16$, $1 \cdot 45)$ and $\mathrm{OR}=1 \cdot 09,95 \% \mathrm{CI}(1 \cdot 05,1 \cdot 13)$, respectively).

\section{Discussion}

Data from a large, nationally representative sample show that eating or drinking $<1 \mathrm{~h}$ prior to weekday bedtime are associated with 1.8-fold higher odds of long sleep duration $(>9 \mathrm{~h}$ ) and nearly twofold higher odds of reported WASO $\geq 30 \mathrm{~min}$. Gender differences were observed in sleep duration such that women in comparison with men who ate or drank before bed had a stronger positive association with sleep duration. While eating or drinking $<1 \mathrm{~h}$ prior to bedtime was associated with over twofold higher odds of WASO in men and women, this association was more pronounced in men. Alternatively, these 
Table 4. Associations of eating or drinking prior to bedtime with weekdays sleep duration among participants of the American time use survey who did not report wake after sleep onset (WASO)

(Odds ratio and $95 \%$ confidence intervals)

\begin{tabular}{|c|c|c|c|c|c|}
\hline \multicolumn{2}{|c|}{ Sleep duration $\dagger$} & \multicolumn{2}{|c|}{ Short sleepł } & \multicolumn{2}{|c|}{ Long sleep } \\
\hline Beta & $95 \% \mathrm{Cl}$ & Odds ratio & $95 \% \mathrm{Cl}$ & Odds ratio & $95 \% \mathrm{Cl}$ \\
\hline
\end{tabular}

All respondents

Ate $<1 \mathrm{~h}$ before bedtime

Crude model

$3027,33^{*}$

Odds ratio

Adjusted model§

29

$26,32^{*}$

0.90

$0.84,0.97^{*}$

1.54

$1 \cdot 44,1 \cdot 64^{*}$

Women

Ate $<1 \mathrm{~h}$ before bedtime

Crude model

$37 \quad 32,42$

0.88

$0.81,0.95^{\star}$

$1 \cdot 66,1 \cdot 90^{*}$

Adjusted model§

37
35

$32,42^{*}$
$30,39 *$

0.85

$0.76,0.95^{*}$

1.77

$1 \cdot 45,1 \cdot 74^{*}$

Men

Ate $<1 \mathrm{~h}$ before bedtime

Crude mode

$2521,30^{*}$

0.84

$0.75,0.94^{*}$

1.59

$1.63,1.97^{*}$

Adjusted model§

$20,28^{*}$

0.92

$0.84,1.02$

1.79

$1.41,1.68^{*}$

* Statistically significant at $P<0.05$; WASO, wake after sleep onset.

† From a linear regression model with sleep duration in minutes as the outcome and eating or drinking $<1 \mathrm{~h}$ before bed as a dichotomous predictor.

‡ From a multinomial logistic model with short sleep duration, sufficient sleep duration and long sleep duration as categorical outcomes (sufficient sleep was the reference) and eating

or drinking $<1 \mathrm{~h}$ before bed as a dichotomous predictor.

$\S$ Adjusted for gender, age, race, education, work status, cohabitation, the presence of children $<18$ years in the household, day of the week and survey year.

Table 5. Timing of eating or drinking prior to bedtime in relation to sleep duration and wake after sleep onset (WASO) among 124239 participants of the American time use survey

(Odds ratio and $95 \%$ confidence intervals)

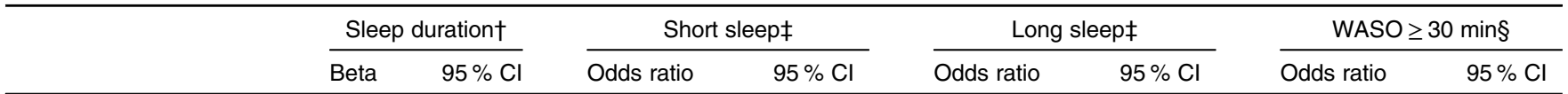

All respondents

Timing of eating or drinking

Crude model

\begin{tabular}{|c|c|c|c|c|c|c|c|c|}
\hline$<1$ hour & 30 & $27,33^{*}$ & 0.90 & $0.83,0.96^{*}$ & 1.55 & $1.45,1.65^{\star}$ & $2 \cdot 00$ & $1 \cdot 72,2 \cdot 33^{\star}$ \\
\hline$<2$ hours & 28 & $26,30^{*}$ & 0.74 & $0.70,0.77^{\star}$ & 1.29 & $1 \cdot 24,1 \cdot 35^{\star}$ & $1 \cdot 81$ & $1.62,2.02^{*}$ \\
\hline$<3$ hours & 28 & $26,29^{*}$ & 0.63 & $0.61,0.65^{\star}$ & $1 \cdot 17$ & $1 \cdot 13,1 \cdot 21^{*}$ & 1.65 & $1 \cdot 50,1 \cdot 81^{*}$ \\
\hline \multicolumn{9}{|c|}{ Adjusted modelll } \\
\hline$<1$ hour & 29 & $26,32^{*}$ & 0.88 & $0.81,0.94^{*}$ & 1.79 & $1.67,1.91^{*}$ & $2 \cdot 26$ & $1.93,2.64^{*}$ \\
\hline$<2$ hours & 30 & $28,31^{*}$ & 0.73 & $0.70,0.77^{\star}$ & 1.60 & $1.51,1.65^{\star}$ & $2 \cdot 01$ & $1 \cdot 80,2 \cdot 25^{\star}$ \\
\hline$<3$ hours & 31 & $30,33^{*}$ & 0.63 & $0.61,0.66^{*}$ & 1.48 & $1.43,1.54^{*}$ & 1.80 & $1.63,1.99^{*}$ \\
\hline$<4$ hours & 30 & $29,32^{*}$ & 0.59 & $0.57,0.61^{*}$ & 1.33 & $1 \cdot 28,1 \cdot 37^{*}$ & 1.55 & $1 \cdot 40,1 \cdot 71^{*}$ \\
\hline$<5$ hours & 26 & $25,28^{*}$ & 0.60 & $0.58,0.62^{*}$ & 1.17 & $1 \cdot 13,1 \cdot 21^{*}$ & 1.39 & $1.26,1.55^{\star}$ \\
\hline$<7$ hours & 16 & $14,18^{*}$ & 0.72 & $0.69,0.75^{\star}$ & 1.06 & $1.01,1.10^{*}$ & $1 \cdot 28$ & $1 \cdot 14,1.45^{\star}$ \\
\hline
\end{tabular}

Women

Timing of eating or drinking

Crude model

\begin{tabular}{|c|c|c|c|c|c|c|c|c|}
\hline \\
\hline$<1$ hour & 37 & $32,41^{\star}$ & 0.85 & $0.76,0.95^{\star}$ & $1 \cdot 60$ & $1.46,1 \cdot 75^{\star}$ & 1.94 & $1 \cdot 58,2 \cdot 37^{\star}$ \\
\hline$<2$ hours & 32 & $29,34^{*}$ & 0.70 & $0.66,0.75^{\star}$ & 1.32 & $1 \cdot 24,1.39^{*}$ & 1.66 & $1.45,1.92^{*}$ \\
\hline$<3$ hours & 32 & $30,34^{*}$ & 0.59 & $0.56,0.62^{*}$ & 1.22 & $1 \cdot 16,1 \cdot 27^{*}$ & 1.60 & $1.42,1 \cdot 80^{*}$ \\
\hline \multicolumn{9}{|c|}{ Adjusted modelll } \\
\hline$<1$ hour & 35 & $30,39^{\star}$ & 0.84 & $0.75,0.94^{\star}$ & $1 \cdot 80$ & $1.63,1.97^{*}$ & $2 \cdot 03$ & $1 \cdot 66,2 \cdot 49^{*}$ \\
\hline$<2$ hours & 32 & $30,35^{\star}$ & 0.71 & $0.66,0.76^{*}$ & 1.59 & $1.49,1.69^{*}$ & $1 \cdot 74$ & $1 \cdot 50,2 \cdot 01^{*}$ \\
\hline$<3$ hours & 34 & $33,36^{*}$ & 0.60 & $0.57,0.64^{*}$ & 1.54 & $1.47,1.61^{*}$ & 1.66 & $1.47,1.87^{*}$ \\
\hline \multicolumn{9}{|l|}{ Men } \\
\hline \multicolumn{9}{|c|}{ Timing of eating or drinking } \\
\hline$<1$ hour & 26 & $22,30^{*}$ & 0.91 & $0.83,1.01$ & 1.55 & $1.42,1.69^{\star}$ & $2 \cdot 32$ & $1 \cdot 83,2 \cdot 93^{*}$ \\
\hline$<2$ hours & 26 & $23,29^{*}$ & 0.76 & $0.71,0.81^{*}$ & $1 \cdot 30$ & $1 \cdot 22,1 \cdot 38^{*}$ & $2 \cdot 24$ & $1 \cdot 88,2 \cdot 68^{*}$ \\
\hline$<3$ hours & 24 & $22,26^{*}$ & 0.66 & $0.63,0.70^{*}$ & $1 \cdot 13$ & $1.07,1.18^{\star}$ & 1.86 & $1 \cdot 57,2 \cdot 19^{*}$ \\
\hline \multicolumn{9}{|c|}{ Adjusted modelll } \\
\hline$<1$ hour & 25 & $21,29^{\star}$ & 0.90 & $0.82,0.99^{\star}$ & 1.78 & $1.62,1.95^{\star}$ & $2 \cdot 64$ & $2 \cdot 08,3 \cdot 36^{*}$ \\
\hline$<2$ hours & 27 & $24,30^{\star}$ & 0.75 & $0.70,0.81^{*}$ & 1.57 & $1.47,1.68^{*}$ & $2 \cdot 56$ & $2 \cdot 13,3 \cdot 01^{*}$ \\
\hline$<3$ hours & 28 & $26,30^{*}$ & 0.66 & $0.62,0.69^{*}$ & 1.41 & $1.34,1.49^{\star}$ & 2.09 & $1 \cdot 77,2 \cdot 48^{*}$ \\
\hline
\end{tabular}

* Statistically significant at $P<0.05$; WASO, wake after sleep onset.

† From a linear regression model with sleep duration in minutes as the outcome and timing of eating or drinking before bedtime as a dichotomous predictor, $<1 \mathrm{~h},<2 \mathrm{~h},<3 \mathrm{~h}$ and so forth.

† From a multinomial logistic model with short sleep duration, sufficient sleep duration and long sleep duration as categorical outcomes (sufficient sleep was the reference) and timing of eating or drinking before bedtime as a dichotomous predictor, $<1 \mathrm{~h},<2 \mathrm{~h},<3 \mathrm{~h}$ and so forth.

§ From a logistic regression model with WASO $\geq 30 \mathrm{~min}$ as the dichotomous outcome and timing of eating or drinking before bedtime as a dichotomous predictor, $<1 \mathrm{~h},<2 \mathrm{~h},<3 \mathrm{~h}$ and so forth.

II Adjusted for gender, age, race, education, work status, cohabitation, the presence of children $<18$ years in the household, day of the week and survey year. 
findings suggest that refraining from eating or drinking at least $1 \mathrm{~h}$ prior to bedtime is protective against WASO. Analysis of WASO as a continuous outcome associated eating or drinking $<1 \mathrm{~h}$ prior to bedtime with an increase of $13 \mathrm{~min}$ of WASO only in men. As the interval between eating or drinking and bedtime lengthens, the negative impact of eating or drinking prior to bedtime on WASO and long sleep duration is attenuated.

Surprisingly, there are limited investigations on the potential impact of eating or drinking before bedtime on sleep duration, WASO and sleep quality. Prior investigations have primarily examined dietary composition of evening meals in relation to sleep measures and corroborated potential links between evening food intake and subsequent sleep. For example, in toddlers, higher carbohydrate intake in the evening meal was associated with longer sleep duration ${ }^{(31)}$. A study of 45 men with obstructive sleep apnoea and obesity associated higher food intake in the evening period with lower sleep efficiency, lower slow wave sleep, more arousals and a greater apnea-hypopnoea index ${ }^{(32)}$. Among fifty-two men in Brazil, higher nocturnal fat intake (including dinner plus late-night snack) was associated with worse sleep quality, including lower sleep efficiency, longer sleep latency and higher WASO. Women with higher total energetic intake at night, typically 30-60 min before bed, had higher sleep latency and lower sleep efficiency ${ }^{(25)}$, but no associations were observed between nocturnal total energetic intake and sleep among men. These results align with the findings of the present study that the association between eating or drinking before bed and sleep duration was stronger in women. Other studies have shown that snacking patterns, which often include snacking after dinner and up until bedtime, are associated with irregular sleep patterns, both shorter ${ }^{(24,33)}$ and longer than recommended sleep duration for adults $(7-9 \mathrm{~h})^{(27)}$.

While eating or drinking closer to bedtime is discouraged, this study demonstrated the negative influence of eating or drinking on sleep duration and WASO at different interval lengths in relation to bedtimes, i.e., $<1,<2$ and $<3 \mathrm{~h}$ prior to bedtime. Our results suggest that although associations between eating or drinking and sleep outcomes remained significant, among women and men, regardless of mealtime, effect estimates were attenuated as eating or drinking activities were reported further away from bedtime. This trend persisted as intervals between eating or drinking and bedtime continued expanding to $<4,<5$, $<6$ and $<7 \mathrm{~h}$. While the influence of eating or drinking on both short and long sleep duration and WASO was most pronounced when reported $<1 \mathrm{~h}$ prior to bedtime, eating or drinking within 4-6 h prior to bedtime confers the highest likelihood for optimal sleep.

The positive association between eating before bedtime and longer sleep duration ( $>10$ for $15-17$ years teens, $>9$ for adults or $>8$ for older adults) observed in the present study was not in the expected direction. These findings could have several potential interpretations. First, longer self-reported sleep duration could actually indicate efforts to compensate after the experience of more sleep difficulties, such as unsuccessful initiation or maintenance of sleep. The association we report between eating before bed and higher odds of WASO supports this interpretation. Indeed, one of the often-cited reasons for not consuming a large meal before bed or certain types of foods (e.g. spicy food) ${ }^{(34)}$ is that digestive symptoms such as heartburn could disturb sleep ${ }^{(35)}$. Similarly, the consumption of alcohol prior to sleep can adversely affect the quality and continuity of sleep, and caffeine can delay the initiation of sleep ${ }^{(21)}$. Alternatively, the association between eating before bed and longer sleep duration could be attributed to foods that enhance sleepiness. Consumption of certain foods or beverages before bedtime, such as melatonin-enhanced milk, could support longer sleep duration ${ }^{(34)}$. However, the present analysis is unable to disentangle potential food-specific mechanisms as participants were not required to record the type of food consumed. Nonetheless, the possibility remains that no cause-and-effect relationship exists between eating or drinking before bedtime. For example, the associations could reflect clustering of unhealthy habits in both sleep and diet, as these behaviours are often intertwined ${ }^{(36)}$. Further, the association between eating or drinking $<1 \mathrm{~h}$ before bedtime and WASO may reflect nocturia, a common sleep disruption, after ingestion of liquids close to bedtime.

This study has several strengths. ATUS is a large, nationally representative survey with over $40 \%$ response rate. Of particular significance, ATUS collects detailed reports of a 24-h period for USA residents along the age continuum, from 15 to 85 years. These detailed data allow the examination of eating or drinking behaviours up to the reported bedtime, as well as sleep timing and waking events during the night. Real-time documentation of eating and sleeping activities avoids recall bias, an inherent limitation of many surveys, particularly for estimated sleep duration. In addition to daily and nocturnal activities, ATUS also collects extensive socio-demographic information now used to adjust for many potentially relevant confounders. Stratification of analysis by weekdays and weekend respondents allowed to identify distinct eating and sleep behaviours as well as to dilute potential confounding related to daylight savings.

However, the present study is not without limitations. As with any cross-sectional survey, the observed associations from one day may not represent habitual sleep and eating behaviours. However, the random assignment of respondents across weekdays and the large sample size allows representation of weekday-specific activities across genders, ages, socio-economic status and regions. Despite the real-time reporting, self-report can introduce inaccuracies. For example, in the estimation of the amount of time spent awake during the night, participants could have rounded their responses. Further inaccuracies in reported sleep duration could result in overestimation or underestimation of sleep duration, based on actual sleep duration. For example, comparisons of objective and self-report sleep duration have suggested that short sleepers $(\leq 6 \mathrm{~h}$ ) were likely to underestimate their sleep duration, while those who slept more than $6 \mathrm{~h}$ overestimated the amount of their sleep ${ }^{(37)}$. Nonetheless, we would not expect these measurement errors to be differential with respect to eating behaviours. The present analysis focused on sleep duration and WASO and did not account for sleep timing. Another limitation of ATUS is the absence of data on depressed mood, which can alter food consumption and sleep behaviour. Moreover, the type and amount of food or beverage participants consumed before bed may influence subsequent sleep. In particular, information 
on alcohol or caffeine consumption was not available. While the ATUS includes a separate module with information about the type of foods consumed by respondents, the timing of those eating activities is missing or they are reported as secondary activity along primary activities unrelated to eating or drinking. Given what is well known about the standard American diet, many of the food items consumed before bed were likely neither healthy nor fresh foods, but rather processed and energy-dense snack items ${ }^{(38,39)}$. The proportion of ATUS respondents who reported WASO seems low, but likely attributed to the self-report method, as polysomnography was not conducted. Finally, data on sleep latency or sleep quality were not reported. Information on specific types of food consumed as well as a more refined examination of sleep characteristics could aid in the formulation of evidence-based recommendations regarding food consumption before bed.

\section{Conclusion}

The present study provides population-level evidence that eating or drinking $<1 \mathrm{~h}$ prior to bedtime could have negative impact on WASO but increases sleep duration. Moreover, the further eating or drinking reported from bedtime, the lower odds of short and long sleep duration and WASO observed. These findings suggest that earlier timing of eating or drinking in relation to bedtime - between 4 and $6 \mathrm{~h}$ - increases the likelihood of optimal sleep duration. Future investigations of specific food and beverages in relation to sleep duration and quality could generate nutritional recommendations that benefit sleep health. Although these cross-sectional data cannot prove cause-and-effect relationships, they do help define the magnitude of the potential problem. If eating or drinking before bedtime do make sleep less efficient in essence - longer, with more awakenings - then the magnitude of the impact appears to be substantial. This motivates additional prospective research to assess for any underlying causative pathway.

\section{Acknowledgements}

Mr. S. I. I. and Drs. E. J., K. S. and L. M. O'B. have nothing to disclose; Dr. R. D. C. reports receiving research grant support from the NIH (U01 NS099043, R01 HL105999, T32 HL110952 and others for which he has not been a PI). He serves as an editor and author for UpToDate. He has produced copyrighted material, patents and patents pending, owned by the University of Michigan, focused on assessment or treatment of sleep disorders. He has served on the Boards of Directors for the American Academy of Sleep Medicine, Associated Professional Sleep Societies, International Pediatric Sleep Association and the non-profit Sweet Dreamzzz and on an advisory board for the non-profit Pajama Program; Dr. K. L. K. reports grants from NIH NIA (P01A1011412 and AG059291) and NHLBI (R01HL141881); Dr. G. L. D. reports grants from National Heart, Lung, and Blood Institute (K01 HL144914 NIH/NIHLBI).

G. L. D., E. J. formulated the research question and co-drafted the manuscript; K. S. designed the study and guided the statistical analysis; S. I. I. conducted all statistical analyses and co-drafted the manuscript; and L. M. O., R. D. C. and K. L. K. interpreted the data and critically revised the draft.

The study was conducted at the University of Michigan, Ann Arbor. All authors have seen and approved the manuscript, and all authors have no conflict of interest.

\section{References}

1. Panel CC, Watson NF, Badr MS, et al. (2015) Joint consensus statement of the American Academy of Sleep Medicine and Sleep Research Society on the recommended amount of sleep for a healthy adult: methodology and discussion. J Clin Sleep Med 38, 1161-1183.

2. Knutson KL (2010) Sleep duration and cardiometabolic risk: a review of the epidemiologic evidence. Best Pract Res Clin Endocrinol Metab 24, 731-743.

3. Jansen EC, Dunietz GL, Chervin RD, et al. (2018) Adiposity in adolescents: the interplay of sleep duration and sleep variability. J Pediatr 203, 309-316.

4. Short MA, Booth SA, Omar O, et al. (2020) The relationship between sleep duration and mood in adolescents: a systematic review and meta-analysis. Sleep Med Rev 52, 101311.

5. Patel SR, Blackwell T, Redline S, et al. (2008) The association between sleep duration and obesity in older adults. Int $J$ Obes 32, 1825-1834.

6. Jike M, Itani O, Watanabe $\mathrm{N}$, et al. (2018) Long sleep duration and health outcomes: a systematic review, meta-analysis and meta-regression. Sleep Med Rev 39, 25-36.

7. Ford ES, Cunningham TJ \& Croft JB (2015) Trends in self-reported sleep duration among US adults from 1985 to 2012. Sleep 38, 829-832.

8. Liu Y, Wheaton AG, Chapman DP, et al. (2016) Prevalence of healthy sleep duration among adults - United States, 2014. Morbidity Mortality Wkly Rep 65, 137-141.

9. Basner M \& Dinges DF (2018) Sleep duration in the United States 2003-2016: first signs of success in the fight against sleep deficiency? Sleep 41, zsy012.

10. Lineberger MD, Carney CE, Edinger JD, et al. (2006) Defining insomnia: quantitative criteria for insomnia severity and frequency. Sleep 29, 479-485.

11. Harvey AG, Stinson K, Whitaker KL, et al. (2008) The subjective meaning of sleep quality: a comparison of individuals with and without insomnia. Sleep 31, 383-393.

12. Mai E \& Buysse DJ (2008) Insomnia: prevalence, impact, pathogenesis, differential diagnosis, and evaluation. Sleep Med Clin 3, 167-174.

13. de Zambotti M, Goldstone A, Colrain IM, et al. (2018) Insomnia disorder in adolescence: diagnosis, impact, and treatment. Sleep Med Rev 39, 12-24.

14. Dunietz GL, Swanson LM, Jansen EC, et al. (2018) Key insomnia symptoms and incident pain in older adults: direct and mediated pathways through depression and anxiety. Sleep 41, zsy125.

15. Morin CM \& Jarrin DC (2013) Epidemiology of insomnia: prevalence, course, risk factors, and public health burden. Sleep Med Clin 8, 281-297.

16. Park EM, Meltzer-Brody S \& Stickgold R (2013) Poor sleep maintenance subjective sleep quality are associated postpartum maternal depression symptom severity. Arch Women Mental Health 16, 539-547.

17. Buysse DJ, Reynolds CF, Monk TH, et al. (1989) The Pittsburgh Sleep Quality Index: a new instrument for psychiatric practice and research. Psychiatr Res 28, 193-213.

18. Posner D \& Gehrman PR (2011) Sleep Hygiene. Behavioral Treatments for Sleep Disorders., pp. 31-43. London: Elsevier. 
19. Mastin DF, Bryson J \& Corwyn R (2006) Assessment of sleep hygiene using the Sleep Hygiene Index. J Behav Med 29, 223-227.

20. Zarcone V (2000) Sleep Hygiene. Principles and Practice of Sleep Medicine 3rd ed., pp. 657-661. Philadelphia: WB Saunders.

21. Irish LA, Kline CE, Gunn HE, et al. (2015) The role of sleep hygiene in promoting public health: a review of empirical evidence. Sleep Med Rev 22, 23-36.

22. Young DR, Sidell MA, Grandner MA, et al. (2020) Dietary behaviors and poor sleep quality among young adult women: watch that sugary caffeine! Sleep Health 6, 214-219.

23. Chung N, Bin YS, Cistulli PA, et al. (2020) Does the proximity of meals to bedtime influence the sleep of young adults? A cross-sectional survey of university students. Int J Environ Res Public Health 17, 2677.

24. Kant AK \& Graubard BI (2014) Association of self-reported sleep duration with eating behaviors of American adults: NHANES 2005-2010. Am J Clin Nutr 100, 938-947.

25. Crispim CA, Zimberg IZ, dos Reis BG, et al. (2011) Relationship between food intake and sleep pattern in healthy individuals. J Clin Sleep Med 7, 659-664.

26. Lopes T, Borba ME, Lopes R, et al. (2019) Eating late negatively affects sleep pattern and apnea severity in individuals with sleep apnea. J Clin Sleep Med 15, 383-392.

27. Kim S, DeRoo LA \& Sandler DP (2011) Eating patterns and nutritional characteristics associated with sleep duration. Public Health Nutr 14, 889-895.

28. Hamermesh DS, Frazis H \& Stewart J (2005) Data watch: the American time use survey. J Econ Perspect 19, 221-232.

29. Hirshkowitz M, Whiton K, Albert SM, et al. (2015) National Sleep Foundation's sleep time duration recommendations: methodology and results summary. Sleep Health 1, 40-43.
30. Schutte-Rodin S, Broch L, Buysse D, et al. (2008) Clinical guideline for the evaluation and management of chronic insomnia in adults. I Clin Sleep Med 4, 487-504.

31. Diethelm K, Remer T, Jilani H, et al. (2011) Associations between the macronutrient composition of the evening meal and average daily sleep duration in early childhood. Clin Nutr 30, 640-646.

32. de Melo CM, Del Re MP, Dos Santos Quaresma MVL, et al. (2019) Relationship of evening meal with sleep quality in obese individuals with obstructive sleep apnea. Clin Nutr ESPEN 29, 231-236.

33. Castro MA, Garcez MR, Pereira JL, et al. (2019) Eating behaviours and dietary intake associations with self-reported sleep duration of free-living Brazilian adults. Appetite 137, 207-217.

34. St-Onge MP, Mikic A \& Pietrolungo CE (2016) Effects of diet on sleep quality. Adv Nutr 7, 938-949.

35. Calleja JL, Bixquert $M$ \& Maldonado J (2007) Impact of nocturnal heartburn on quality of life, sleep, and productivity: the SINERGE study. Dig Dis Sci 52, 2858-2865.

36. Jansen EC, Dunietz GL, Tsimpanouli M-E, et al. (2018) Sleep, diet, and cardiometabolic health investigations: a systematic review of analytic. Strategies 7, 235-258.

37. Dunietz GL, Jansen EC, Hershner S, et al. (2021) Parallel assessment challenges in nutritional and sleep epidemiology. Am J Epidemiol 190, 954-961.

38. Kant AK (2018) Eating patterns of US adults: meals, snacks, and time of eating. Phys Behav 193, 270-278.

39. Sebastian RS, Enns CW \& Goldman JD (2011) Snacking Patterns of US Adults: What We Eat in America, NHANES 2007-2008. Food Surveys Research Group Dietary Data Brief No. 4. https://www.ars.usda.gov/ARSUserFiles/80400530/ pdf/dbrief/4_adult_snacking_0708.pdf (accessed June 2011). 